Running head: SELF-REGULATION \& AGGRESSION

\title{
Self-Regulation Deficits Explain the Link between Reactive Aggression and Internalizing and Externalizing Behavior Problems in Children
}

\author{
Bradley A. White ${ }^{1}$, Matthew A. Jarrett ${ }^{2}$, and Thomas H. Ollendick ${ }^{1}$ \\ ${ }^{1}$ Department of Psychology, Virginia Tech, \\ Blacksburg, Virginia \\ ${ }^{2}$ Department of Psychology, University of Alabama, \\ Tuscaloosa, Alabama
}

Address correspondence concerning this article to Bradley White, Department of

Psychology, Virginia Tech, 109 Williams Hall (0436), Blacksburg, VA 24061; +1 (540)231-

1382; fax: +1(540)231-3652; e-mail: whiteba@vt.edu. 


\begin{abstract}
Childhood aggression is often associated with significant psychosocial maladjustment; however, adjustment difficulties may vary based on the function of aggression. The present study used the Behavior Rating Inventory of Executive Function (BRIEF; Gioia, Isquith, Guy, \& Kenworthy, 2000) to examine whether difficulties in particular domains of self-regulation serve as common mechanisms in the association between reactive (versus proactive) aggression and internalizing or externalizing adjustment problems in clinic-referred children. Reactive aggression was associated with poorer behavioral regulation and metacognition, whereas proactive aggression was not associated with poorer self-regulation. Further, the association between reactive aggression and adjustment problems, both internalizing and externalizing, was accounted for by poorer behavioral regulation and metacognitive skills. Gender, age, ADHD diagnosis, IQ, and psychotropic medication status did not account for the results. These findings suggest that self-regulation skills influence adjustment problems in reactively aggressive youth and may be important targets of intervention for such children.
\end{abstract}

Key words: self-regulation, aggression, externalizing, internalizing, children 
Self-Regulation Deficits Explain the Link between Reactive Aggression and Internalizing and Externalizing Behavior Problems in Children

Comorbidity is frequently observed both within and between two broad domains of childhood maladjustment, externalizing problems (e.g., hyperactivity, rule-breaking behaviors, and aggression) and internalizing problems (e.g., anxiety, depression, somatic complaints, and withdrawal; Angold, Costello, \& Erkanli, 1999; Kessler, Chiu, Demler, \& Walters, 2005). Within the externalizing domain, childhood aggression is often associated with a host of other externalizing problems as well as internalizing problems. However, the degree of association may vary by the intent or function of aggression (Card \& Little, 2006; Marsee \& Frick, 2007), which may reflect different underlying mechanisms.

Over the past two decades, an important distinction has been made between two functional subtypes of aggression, reactive and proactive (Dodge \& Coie, 1987). Reactive aggression is an affect-laden defensive or retaliatory response to perceived provocation or threat, whereas proactive aggression is a "cold-blooded" instrumental offensive behavior used in the absence of provocation or anger to achieve a desired goal (Dodge \& Coie, 1987; Winstok, 2009). Measures of these two functions are moderately correlated but also distinguishable (Ollendick, Jarrett, Wolff, \& Scarpa, 2009). Reactive aggression is more consistent with the frustrationaggression hypothesis (Berkowitz, 1978; Dollard, Miller, Doob, Mower, \& Sears, 1939) and is characterized by heightened physiological reactivity and poorer control of affect and impulses, whereas proactive aggression is more consistent with Bandura's (1973) social learning theory and is driven by expectation of external rewards and associations with deviant peers (Card \& Little, 2006; Dodge, Lochman, Harnish, Bates, \& Pettit, 1997; Hubbard et al. 2002; LopezDuran, Olson, Hajal, Felt, \& Vazquez, 2009; Poulin \& Boivin, 2000; Price \& Dodge, 1989; Prinstein \& Cillessen, 2003). 
Compared to proactive aggression, reactive aggression is more often related to psychosocial maladjustment, including internalizing problems, and attention-deficit/hyperactivity disorder (ADHD) symptoms, whereas proactive aggression is more often associated with delinquency and callous-unemotional traits (Card \& Little, 2006; Marsee \& Frick, 2007). Reactive aggression has also been linked to self-regulation difficulties, including emotion dysregulation and deficits in executive functioning. Self-regulation can be defined as the capacity to control and alter ones responses in the service of ones' goals, including inhibiting and overriding prepotent (immediately or previously reinforced) responses or urges, often in an effortful and deliberate fashion (Barkley, 2001; Vohs \& Baumeister, 2004). Effective selfregulation depends in part on executive functions, a collection of cognitive processes that facilitate purposeful behavior, effective problem solving, and goal attainment by guiding, directing, and managing emotions, behavior, and other mental processes (Seguin \& Zelazo, 2005; Stuss \& Benson, 1987; Welsh \& Pennington, 1988).

Giancola and colleagues were among the first to establish the link between reactive aggression and poorer executive functions in boys at risk for substance abuse using laboratorybased executive function measures (Giancola, Moss, Martin, Kirisci, \& Tarter, 1996). More recently, Ellis, Weiss and Lochman (2009) tested the hypothesis that reactive aggression, in contrast to proactive aggression, stems in part from poorer executive functions. They based this hypothesis on research by Richards and Gross (2000) who indicated that executive functions such as behavioral inhibition are recruited to facilitate regulation of negative affect. It was hypothesized that such skills may be lagging in children with reactive aggression, given the angry and hostile responding that characterizes this functional subtype. Utilizing several performance-based measures of executive functions, Ellis and colleagues demonstrated that 
deficits in inhibitory control on the Stroop task were associated with reactive aggression, particularly in individuals who tended to encode hostile cues. Recent research on adults has demonstrated similar associations between deficits in executive functions and emotional regulation difficulties (e.g., maternal reactive negativity and working memory deficits, DeaterDeckard, Sewell, Petrill, \& Thompson, 2010). Others have similarly suggested that selfregulation deficits are more relevant to reactive than proactive aggression, because only reactive aggression results from the failure to override an impulsive urge to inflict harm, whereas proactive aggression is a premeditated behavior driven by instrumental goals (DeWall, Finkel, \& Denson, 2011). Effortful control, a temperament-based self-regulation construct that reflects attentional and inhibitory control (Rothbart \& Bates, 2006) and conceptually overlaps with executive functions (Zhou, Chen \& Main, 2011), has similarly been found to uniquely and inversely relate to reactive and not proactive aggression (Rathert, Fite, Gaertner, \& Vitulano, 2011). In addition to protecting against reactive aggression, the capacity to self-regulate is believed to promote resilience against other externalizing as well as internalizing adjustment problems (e.g., Dishion \& Connell, 2006).

The present study extends the research on relationships among self-regulation, functions of aggression, and psychological adjustment. Specifically, we investigated the role of selfregulation deficits as a common mechanism in the association between reactive (versus proactive) functions of aggression and internalizing and externalizing adjustment problems. In contrast to prior studies using laboratory-based measures of executive functions, we selected a frequently used clinical assessment measure of children's self-regulation deficits in natural contexts, the Behavior Rating Inventory of Executive Function (BRIEF; Gioia, Isquith, Guy, \& Kenworthy, 2000). Scores on the BRIEF are based on parent or teacher ratings of overt child 
behaviors that are believed to reflect executive functioning and self-regulation difficulties as they are expressed in everyday settings. The BRIEF has been used to examine such deficits in a variety of childhood conditions, including autism spectrum disorders (e.g., Zingerevich \& LaVesser, 2009), traumatic brain injury (e.g., Conklin, Salorio \& Slomine, 2008), epilepsy (Parrish et al., 2007), diabetes (Bagner, Williams, Geffken, Silverstein, \& Storch, 2007), and ADHD (e.g., McCandless \& O’Laughlin, 2007; Toplack, Bucciarelli, Jain, \& Tannock, 2009). To our knowledge, the present study is the first to examine self-regulation deficits in functional subtypes of aggression using the BRIEF. In turn, the first aim of our study was to examine these self-regulation deficits in functional subtypes of aggression.

A secondary and exploratory aim of the study was to determine whether particular domains of self-regulation deficits account for the relationship between reactive aggression and behavioral problems. The BRIEF clinical scales assess two broad indices: behavioral regulation and metacognition (Gioia et al., 2000). Behavioral regulation comprises inhibitory control (ability to resist or inhibit an impulse), shifting (flexible transitioning and problem-solving), and emotional control (modulating emotional responses). Metacognition comprises initiation (independent generation of appropriate responses and strategies), working memory (ability to hold information in mind and work with it), planning and organization (anticipating and managing current and future-oriented task demands and organizing information), organization of materials (ability to organize work and play spaces and keep track of possessions), and monitoring (work-checking and tracking the effect of one's work and impact of one's behavior on others; Gioia et al., 2000). These two broad indices were examined in the present study, given prior research suggesting that both behavioral regulation and metacognition may play a role in the emotion modulation difficulties seen in reactive aggression (Deater-Deckard et al., 2010; 
Ellis et al., 2009), in contrast to proactive aggression, which does not appear to reflect selfregulation deficits (DeWall, Finkel, \& Denson, 2011; Rathert, Fite, Gaertner, \& Vitulano, 2011). The present study also advances the current literature in several additional ways. First, prior research on relationships between aggression and self-regulation deficits in children has tended to utilize all-male samples (e.g., Ellis et al., 2009; Giancola et al., 1996). Second, most of the research on reactive and proactive aggression has focused on children in the community (e.g., Ellis et al., 2009), whereas the BRIEF has been utilized more often in mixed clinical samples (e.g., Bodnar, Prahme, Cutting, Denckla, \& Mahone, 2006). Among the few studies of reactive and proactive aggression in clinical samples, Connor and colleagues found that both subtypes exist at high levels in clinically-referred boys and girls, but that correlates of reactive and proactive aggression differ by gender (Connor, Steingard, Anderson, Melloni, 2003). We chose to test our predictions on a clinically-referred sample that included both boys and girls to examine whether relationships between functional subtypes of aggression and self-regulation deficits generalize across gender and nature of the sample. Finally, in addition to gender, we also considered children's age, IQ, ADHD, and medication status as potential confounds in light of prior evidence of their association with externalizing and internalizing problems (e.g., Coie \& Dodge, 1998; Hinshaw, Henker, Whalen, Erhardt, \& Dunnington, 1989; Jarrett \& Ollendick, 2008; Schoemaker, Bunte, Wiebe, Espy, Deković, \& Matthys, 2012).

Consistent with past findings (e.g., Card \& Little, 2006; Fite, Stoppelbein \& Greening, 2009), we predicted that reactive aggression would be associated with both internalizing and externalizing adjustment problems, and proactive aggression would be associated with externalizing adjustment problems only (e.g., delinquency and conduct problems). Also based on prior work (Ellis et al., 2009; DeWall et al., 2011), we predicted that self-regulation deficits 
would be associated with reactive but not proactive aggression. Finally, based on studies of selfregulation and resiliency (Dishion \& Connell, 2006), we hypothesized that self-regulation deficits would account for the vulnerability of reactively aggressive children to both externalizing and internalizing adjustment problems.

\section{Method}

\section{Participants}

The current investigation was part of a larger study of approximately 400 children referred for outpatient assessment. Children and their parent(s) presented at an outpatient clinic in southwestern Virginia for a comprehensive psychoeducational and diagnostic assessment. Children were referred by community pediatricians, family practitioners, schools, and mental health professionals for a diverse array of problems. Participants were consecutive referrals and included 85 children ( 54 boys; mean age $=10.00 ; S D=2.82$; range $=6-16$ years $)$ and their parent(s). Exclusion criteria were minimal and included presence of a psychotic disorder or a pervasive developmental disorder. Approximately 95\% of the children were Caucasian, $2 \%$ Hispanic, $1 \%$ African-American, and 2\% of another ethnicity. Mean Full Scale IQ for the sample was $94.20(S D=14.91)$ based on the Wechsler Intelligence Scale for Children (Wechsler, 1991, 2003). Twenty-one (25\%) participants were receiving at least one psychiatric medication at the time of assessment, primarily for ADHD or for one or more of the anxiety disorders. Sample characteristics including clinical consensus diagnoses are presented in Table 1.

With respect to family characteristics, the sample consisted primarily of families from middle class backgrounds (mean income $=\$ 61,974 ; S D=\$ 47,848$ ), although considerable variability was present. In relation to family structure, $65 \%$ of the children were living with two parents. The remaining children were living with single never-married, divorced, or widowed 
mothers. The majority of mothers $(92 \%)$ and fathers $(75 \%)$ had biological status as a parent, and most of the mothers (97\%) and fathers (95\%) had completed high school.

\section{Measures}

Child Behavior Checklist (CBCL; Achenbach, 1991; 2001). The CBCL is a 113-item paper and pencil questionnaire completed by parents. Parents are asked to indicate how often the behavior described in each item is true of their child using a three-point scale (often/always true, sometimes true, and not true). Achenbach (2001) reported test-retest reliability over a 1-week interval to be .95 for the problem items. The validity of the CBCL/4-18 has been established through repeated factor analyses and associations with other variables of interest (see Achenbach 2001). Only maternal report was used for the current study, given that almost all primary caregivers were mothers $(98 \%)$. Norm-referenced $T$ scores $(M=50, S D=10)$ from the Externalizing and Internalizing scales were used to permit comparisons with other studies. The Externalizing scale measures the frequency of aggressive and delinquent behaviors, whereas the Internalizing scale measures somatic complaints and anxious, depressed, and withdrawn behavior. Higher scores reflect greater behavior problems. For the present study, Cronbach's alphas were high for both the Externalizing $(\alpha=.91)$ and Internalizing $(\alpha=.89)$ scales.

Behavior Rating Inventory of Executive Function - Parent Form (BRIEF; Gioia et al., 2000). The BRIEF consists of 86 items of parent ratings of the child's self-regulation as reflected in specific problem behaviors at home and in school. It yields eight clinical scale scores which load onto two indices, Behavior Regulation (inhibitory control, shifting, emotional control) and Metacognition (initiation, working memory, planning and organization, organization of materials, and monitoring). Higher scale scores on the BRIEF indicate poorer self-regulation in each domain. Maternal report-based $T$ scores $(M=50, S D=10)$ from the Behavioral Regulation 
Index and Metacognition Index were used in the present study to provide a measure of selfregulation deficits in each domain relative to children of the same age and gender from the standardization sample. High internal consistency was found for both the Behavioral Regulation Index $(\alpha=.94)$ and Metacognition Index $(\alpha=.87)$.

Reactive Proactive Aggression Measure (RPA; Dodge \& Coie, 1987). The six items on the RPA provide a measure of reactive and proactive aggression. Mothers used a five-point Likert scale ( 1 = never, 5 = almost always) indicating how frequently each item applied to their child. Three items represent Reactive Aggression ("overreacts angrily to accidents," "when teased, strikes back," and "blames others in fights"), and three items represent Proactive Aggression ("threatens or bullies others," "gets others to gang up on a peer," and "uses physical force to dominate others;" Dodge \& Coie, 1987). The construct validity of this version of the scale has been supported in prior studies (e.g., Vitaro, Brendgen \& Tremblay, 2002). Following prior research, correlates of reactive aggression were assessed independently of proactive aggression and vice versa (e.g., Raine et al., 2006). This approach was used due to the moderate correlation $(r=.65)$ between reactive and proactive aggression in the present study, which is comparable to prior studies (e.g., Polman, de Castro, Koops, van Boxtel, \& Merk, 2007). Standardized residual scores were created, with reactive aggression regressed onto proactive aggression to index purely reactive aggression, and proactive aggression regressed on reactive aggression to index purely proactive aggression. Cronbach's alphas were acceptable for both Reactive $(\alpha=.82)$ and Proactive aggression $(\alpha=.85)$ scales.

Wechsler Intelligence Scale for Children (WISC; Wechsler 1991, 2003). The WISC is an individually administered clinical instrument for assessing the intellectual ability of children aged 6 years through 16 years and 11 months. The mean score for the Full Scale IQ (FSIQ) is 
100 with a standard deviation of 15 . Evidence for adequate reliability and validity of the WISC has been documented (Wechsler, 2003; Prifitera, Saklofske, \& Weiss, 2005). Given the timeframe of the study, which extended over several years, the WISC-III (1991) and WISC-IV (2003) FSIQ were used to assess intellectual ability.

\section{Procedure}

The study was approved by our university's institutional review board (IRB). Prior to the start of the clinical assessment, parents gave consent for the assessment information to be used for research purposes. Assessment sessions included intellectual and achievement testing, a clinical interview including inquiry regarding the child's psychotropic medications, and several self-report and laboratory measures in addition to semi-structured diagnostic interviews conducted separately with the child and parent (see below). A disorder was considered present if the child was assigned a clinical diagnosis during a consensus meeting utilizing multiple measures and multiple informants (see *reference masked for review*, for details). The consensus meeting was attended by a licensed clinical psychologist as well as the child and parent clinicians (trained-to-criterion graduate students in an APA-approved clinical psychology training program) who conducted the assessments.

\section{Data Analysis}

Zero-order correlations with demographic (age, gender), FSIQ, ADHD, and medication status were examined first to identify any potential confounds. ${ }^{1}$ To test our prediction that selfregulation (behavior regulation and metacognition) difficulties explain relationships between aggression and internalizing and externalizing adjustment problems, we conducted a series of hierarchical regression analyses with and without these self-regulation variables included in the model. We followed the traditional approach to test for unique effects of each aggression 
function by running separate regression analyses for residualized reactive and proactive aggression scores (e.g., Raine et al., 2006). Based on analytical recommendations by MacKinnon, Lockwood, Hoffman, West, and Sheets (2002), we then tested the difference in regression coefficients before and after adjusting for each self-regulation variable using Freedman \& Schatzkin's (1992) approach. This approach produces a critical $t$ value as a test of the null hypothesis that the difference between the adjusted and unadjusted regression coefficients for the relationship between the IV and DV is zero $\left(H_{0}: \tau-\tau^{\prime}=0\right)$. To estimate effect sizes, we calculated the percent of total association accounted for by behavioral regulation or metacognition, as indexed by the squared semi-partial correlations for the coefficients representing the associations between aggression and internalizing or externalizing problems $\left(\mathrm{sr}_{\tau}^{2}-\mathrm{sr}_{\tau}^{2}, \mathrm{sr}_{\tau}^{2}\right)$.

Results

Descriptive statistics for the sample are provided in Table 1 and zero-order correlations among all variables are presented in Table 2.

Predictions regarding reactive aggression were considered first, followed by those for proactive aggression. ${ }^{2}$ Descriptive statistics (Table 2) showed that residualized Reactive Aggression (i.e., controlling for Proactive Aggression) correlated in the expected direction with both Internalizing Problems $(r=.21, p=.03)$ and Externalizing Problems $(r=.35, p<.001)$. Reactive Aggression was also associated with poorer self-regulation in terms of both Behavioral Regulation $(r=.48, p<.001)$ and Metacognition $(r=.24, p=.01)$ indices. Regression analyses were then conducted to test the hypothesized roles of behavioral regulation and metacognition as common mechanisms in the observed relationships between reactive aggression and internalizing and externalizing Problems. These analyses are presented in Table 3. 
Analyses were first examined for behavioral regulation. The association between Internalizing Problems and Reactive Aggression became nonsignificant after controlling for Behavioral Regulation Index score $(\beta=-.06, p=.59)$, and the Freedman and Schatzkin (1992) test indicated a significant difference in coefficients $(t=5.16, p<.001)$. Specifically, Behavioral Regulation accounted for $93.3 \%$ of the association between Reactive Aggression and Internalizing Problems, consistent with our prediction of behavioral regulation as a common mechanism. Likewise, the association between Externalizing Problems and Reactive Aggression became nonsignificant after controlling for Behavioral Regulation $(\beta=.01, p=.93)$, and there was a significant difference in coefficients $(t=6.77, p<.001)$. Behavioral Regulation completely accounted for the association between Reactive Aggression and Externalizing Problems.

Analyses for metacognition were considered next. The association between Internalizing Problems and Reactive Aggression was nonsignificant after controlling for Metacognition $(\beta=$ $.01, p=.93)$, and there was a significant difference in coefficients $(t=6.77, p<.001)$. Specifically, Metacognition accounted for $57.8 \%$ of the association between Reactive Aggression and Internalizing Problems. The association between Externalizing Problems and Reactive Aggression remained significant after controlling for Metacognition $(\beta=.30, p=.01)$; however, the change in coefficients was significant $(t=2.01, p=.047)$, with Metacognition accounting for $30.9 \%$ of the association between Reactive Aggression and Externalizing Problems.

The observed relationships were unique to reactive aggression. Residualized Proactive Aggression (i.e. controlling for Reactive aggression) was not associated with Internalizing Problems $(r=.06, p=.31)$. While Proactive Aggression was associated with Externalizing 
Problems $(r=.27, p=.01)$, it was not associated with deficits in Behavioral Regulation $(r=-.01$, $p=.95)$ or Metacognition $(r=.00, p=1.00)$. Likewise, the corresponding Freedman and Schatzkin (1992) tests for the effect of either Behavior Regulation or Metacognition in the association between Proactive Aggression and Internalizing or Externalizing Problems were not significant (all $p$ values $>.10$ ), and neither self-regulation index accounted for a fraction of the association between Proactive Aggression and Externalizing Problems. ${ }^{3}$

\section{Discussion}

Consistent with prior studies (e.g., Fite et al. 2009; Rathert, Fite, Gaertner, \& Vitulano, 2011), reactive aggression was associated with both internalizing and externalizing problems, and proactive aggression was associated with externalizing problems only. Furthermore, poorer self-regulation was associated with reactive but not proactive aggression. As hypothesized, poorer self-regulation appeared to function as a common mechanism in the association between reactive, but not proactive, functions of aggression and internalizing and externalizing problems. Our analyses suggest that self-regulation deficits, both those involving behavioral regulation (modulating behaviors and emotions and shifting cognitive set in a flexible manner) and metacognition (planning, organizing, initiating, and sustaining future-oriented problem solving in working memory), account for the observed relationship between reactive aggression and externalizing and internalizing adjustment problems. We interpret this finding to reflect the important role that self-regulatory processes play in adaptive emotional and behavioral functioning. Interestingly, our findings were generally consistent with those of Ellis and colleagues (2009) despite our use of a commonly implemented parental report measure of selfregulation as it manifests in everyday contexts (i.e., the BRIEF, Gioia et al., 2000), and not a performance- or laboratory-based measure of executive functions as used by Ellis et al. (2009). 
The results support the conceptual validity of the role that self-regulation deficits play in reactively aggressive youth, given that the relationship has now been demonstrated with different assessment methods. Importantly, our study also shows that these relations with self-regulation are above and beyond those accounted for by gender, age, ADHD diagnosis, IQ, or psychotropic medication status. This finding is particularly noteworthy given that many past studies examining self-regulation deficits have failed to control for ADHD status, a critically important variable given the known self-regulation deficits in ADHD (Nigg, 2006).

There are some noteworthy limitations of the present study. First, the reliance on maternal report alone did not permit direct evaluation of the potential influence of shared method variance. However, our findings suggest that shared method variance alone cannot account for our results. For example, there were clear differences in the associations between reactive versus proactive aggression and internalizing problems, and in the associations between reactive versus proactive aggression and self-regulation deficits. Nevertheless, the inclusion of alternate informants (e.g., self- and teacher report) and methods (e.g., laboratory-based measures) would allow for better consideration of method variance. Future studies on aggression and associated adjustment problems may benefit from examining both performance-based tests and report-based measures of self-regulation concurrently.

There are several other limitations to the present study. It was cross-sectional, precluding examination of the temporal relationships among variables. Also, the Dodge and Coie (1987) measure of reactive and proactive aggression does not distinguish forms (e.g., physical vs. relational) and functions (reactive vs. proactive) of aggression as do some newer measures, a confound that could affect study results and interpretation (Little, Jones, Henrich, \& Hawley, 2003). Furthermore, we did not examine social information processing patterns or contextual 
factors (e.g., parental psychological control), which previous studies suggest may enhance or attenuate the effects of self-regulation deficits on subtypes of aggression (e.g., Ellis et al., 2009; Rathert, Fite, Gaertner \& Vitulano, 2011). While it appears that poorer behavioral regulation as indexed by the BRIEF (Gioia, Isquith, Guy, \& Kenworthy, 2000) may account for more variance than metacognition in the associations between reactive aggression and adjustment problems, future studies that simultaneously evaluate these self-regulation indices would permit a more direct comparison of their relative importance. Finally, our sample consisted of clinicallyreferred children who were predominantly Caucasian and middle-class, so our findings may not generalize to other populations. Future studies should address these limitations by utilizing longitudinal or experimental designs with diverse samples, measures that could better distinguish aggression form and function, and measures of potential moderators such as social information processing styles and contextual factors.

Despite these limitations, the present study illustrates how self-regulation difficulties can account for internalizing and externalizing behaviors seen in reactively aggressive children. These findings suggest that self-regulation skills may be an important target of treatment in reactively aggressive children who present with internalizing or externalizing behavior problems. Interventions should emphasize self-regulatory skill development, including handling negative emotional arousal and behavioral impulses in a nonaggressive and flexible manner. One exemplary intervention emphasizing such skill development is The Coping Power Program (Lochman \& Wells, 2002), which includes both child- and parent-training components but focuses primarily on child skill development.

Results of the present study further suggest that self-regulation deficits do not play an important role in the association between proactive aggression and externalizing and 
internalizing behaviors. Other factors, such as callous-unemotional tendencies (e.g., Marsee \& Frick, 2007) or expectation that aggression will produce external rewards (Dodge \& Coie, 1987) may better account for the presence of various externalizing behaviors in proactively aggressive children. Potential treatment implications of this finding may be limited by the fact that it is less common for a child to show elevated proactive aggression without also showing elevated reactive aggression (e.g., Dodge et al., 1997). Nevertheless, our results suggest that children who are predominantly high in proactive aggression may benefit less from approaches targeting selfregulation processes than from other interventions (e.g., those focused on social learning and reinforcement contingencies). Newer approaches to measuring aggression that better differentiate its proactive and reactive functions in children might further illustrate the practical utility of this distinction. 
Self-Regulation Deficits 18

Footnotes

${ }^{1}$ Psychotropic medication status and ADHD diagnostic status were dichotomized (present vs. absent) for analyses.

${ }^{2}$ Although age, gender, and IQ were associated with variables of interest, including these variables as well as ADHD diagnosis and psychotropic medication status as covariates in the regression models did not change the pattern of findings; thus, models without these covariates are reported. Gender was also explored as a potential moderator. Gender did not moderate the association between Reactive Aggression and Internalizing or Externalizing Problems either before or after Behavioral Regulation or Metacognition were added to the models (i.e. the difference in coefficients was consistent for males and females). Therefore, only models without gender as a moderator reported.

${ }^{3}$ Another potential concern when closely related concepts are measured regards shared content across instruments. To address this concern, we first qualitatively evaluated the items on each scale for content overlap. Notable overlap was observed between the first Reactive Aggression item on the RPA (“overreacts angrily to accidents" and several items from the Emotional Control scale of the Behavioral Regulation Index of the BRIEF (e.g., "overreacts to small problems," "has explosive, angry outbursts"). Analyses rerun for the remaining Behavioral Regulation Index items (i.e. Inhibit and Shift scales) excluding Emotional Control produced the same pattern of results, thus findings for the Index scores are reported. Second, we considered bivariate correlations among predictors. The strongest association was observed between the BRIEF Behavioral Regulation Index and CBCL Externalizing Problems $(r=.71)$, of which the Aggressive Behavior scale conceptually and empirically overlapped more strongly with the BRIEF Behavioral Regulation Index $(r=.72)$ than did the Rule-Breaking scale $(r=.51)$. 
Nevertheless, the same pattern of results were found for analyses using just the Aggressive Behavior scale and just the Rule-Breaking scale as were found for the for Externalizing Problems, therefore only the latter are reported.

\section{Acknowledgements}

Special thanks are extended to Matthew Fritz for statistical consultation, and to the children and parents who participated in the study. 


\section{References}

Achenbach, T. M. (1991). Manual for the child behavior checklist/4-18 and 1991 profile. Burlington, VT: University of Vermont, Department of Psychiatry.

Achenbach, T. M. (2001). Manual for the child behavior checklist 4-18 and 2001 profile. Burlington: University of Vermont, Department of Psychiatry.

Angold, A., Costello, E. J., \& Erkanli, A. (1999). Comorbidity. Journal of Child Psychology and Psychiatry, 40, 57-87.

Bagner, D. M., Williams, L. B., Geffken, G. R., Silverstein, J. H., \& Storch, E. A. (2007). Type 1 diabetes in youth: The relationship between adherence and executive functioning. Children's Health Care, 36, 169-179.

Bandura, A. (1973). Aggression: A social learning analysis. Oxford England: Prentice-Hall.

Barkley, R. A. (2001). The executive functions and self-regulation: An evolutionary neuropsychological perspective, Neuropsychology Review, 11, 1-29.

Berkowitz, L. (1978). Whatever happened to the frustration-aggression hypothesis? American Behavioural Scientist, 21, 691-708.

Bodnar, L. E., Prahme, M. C., Cutting, L. E., Denckla, M. B., \& Mahone, E. M. (2006). Construct validity of parent ratings of inhibitory control. Child Neuropsychology, 13, 345-362.

Card, N. A., \& Little, T. D. (2006). Proactive and reactive aggression in childhood and adolescence: A meta-analysis of differential relations with psychosocial adjustment. International Journal of Behavioral Development, 30, 466-480. 
Coie, J. D., \& Dodge, K. A. (1998). Aggression and antisocial behavior. In W. Damon (Series Ed.) \& N. Eisenberg (Vol. Ed.), Handbook of child psychology: Vol. 3. Social, emotional, and personality development (pp. 779-862). New York: Wiley. Conklin, H. M., Salorio, C. F., \& Slomine, B. S. (2008). Working memory performance following paediatric traumatic brain injury. Brain Injury, 22, 847-857.

Connor D. F., Steingard, R. J., Anderson J. J., \& Melloni, R. H. (2003). Gender differences in reactive and proactive aggression. Child Psychiatry and Human Development, 33, 279-294.

Deater-Deckard, K., Sewell, M. D., Petrill, S. A., \& Thompson, L. A. (2010). Maternal working memory and reactive negativity in parenting. Psychological Science, 21, 75-79.

DeWall, C.N., Finkel, E.J., \& Denson, T. F. (2011). Self-control inhibits aggression. Social and Personality Psychology Compass, 5, 458-472.

Dishion, T. J., \& Connell, A. (2006). Adolescents' resilience as a self-regulatory process: Promising themes for linking intervention with developmental science. Annals of the New York Academy of Sciences, 1094, 125-138.

Dodge, K. A., \& Coie, J. D. (1987). Social-information-processing factors in reactive and proactive aggression in children's peer groups. Journal of Personality and Social Psychology, 53, 1146-1158.

Dodge, K. A., Lochman, J. E., Harnish, J. D., Bates, J. E., \& Pettit, G. S. (1997). Reactive and proactive aggression in school children and psychiatrically impaired chronically assaultive youth. Journal of Abnormal Psychology, 106, 37-51.

Dollard, J., Miller, N. E., Doob, L. W., Mowrer, O. H., \& Sears, R. R. (1939). Frustration and aggression. New Haven, CT: Yale University Press. 
Ellis, M. L., Weiss, B., \& Lochman, J. E. (2009). Executive functions in children: Associations with aggressive behavior and appraisal processing. Journal of Abnormal Child Psychology, $37,945-956$.

Fite P. J., Stoppelbein, L., \& Greening, L. (2009). Proactive and reactive aggression in a child psychiatric inpatient population. Journal of Clinical Child and Adolescent Psychology 38,199-205.

Freedman, L. S., \& Schatzkin, A. (1992). Sample size for studying intermediate endpoints within intervention trials of observational studies. American Journal of Epidemiology, 136, 1148 1159.

Giancola, P. R., Moss, H. B., Martin, C. S., Kirisci, L., \& Tarter, R. E. (1996). Executive cognitive functioning predicts reactive aggression in boys at high risk for substance abuse: A prospective study. Alcoholism: Clinical and Experimental Research, 20, 740-744.

Gioia, G. A., Isquith, P. K., Guy, S. C., \& Kenworthy, L. (2000). Behavior rating inventory of executive function. Child Neuropsychology, 6, 235-238.

Hinshaw , S. P., Henker , B., Whalen , C. K., Erhardt , D., \& Dunnington , R. E. (1989). Aggressive, prosocial, and nonsocial behavior in hyperactive boys: Dose effects of methylphenidate in naturalistic settings. Journal of Consulting and Clinical Psychology, 57, 636-643.

Hubbard, J. A., Smithmyer, C. M., Ramsden, S. R., Parker, E. H., Flanagan, K. D., Dearing, K. F., ...Simons, R. F. (2002). Observational, physiological, and self-report measures of children's anger: Relations to reactive versus proactive aggression. Child Development, 73, 1101-1118. 
Jarrett, M. A., \& Ollendick, T. H. (2008). A conceptual review of the comorbidity of attentiondeficit/hyperactivity disorder and anxiety: Implications for future research and practice. Clinical Psychology Review, 28, 1266-1280.

Kessler, R., Chiu, W. T., Demler, O., \& Walters, E. (2005). Prevalence, severity, and comorbidity of 12-month DSM-IV disorders in the National Comorbidity Survey Replication. Arch Gen Psychiatry, 62, 617-627.

Little, T. D., Jones, S. M., Henrich, C. C., \& Hawley, P. H. (2003). Disentangling the 'whys' from the 'whats' of aggressive behaviour. International Journal of Behavioral Development, 27, 122-133. Lochman, J. E., \& Wells, K. C. (2002). The Coping Power Program at the middle school transition: Universal and indicated prevention effects. Psychology of Addictive Behaviors, 16, S40-S54.

Lopez-Duran, N. L., Olson, S. L., Hajal, N. J., Felt, B. T., \& Vazquez, D. M. (2009). Hypothalamic pituitary adrenal axis functioning in reactive and proactive aggression in children. Journal of Abnormal Child Psychology, 37, 169-182.

MacKinnon, D. P., Lockwood, C. M., Hoffman, J. M., West, S. G., \& Sheets, V. (2002). A comparison of methods to test mediation and other intervening variable effects. Psychological Methods, 7, 83-104.

Marsee, M. A., \& Frick, P. J. (2007). Exploring the cognitive and emotional correlates to proactive and reactive aggression in a sample of detained girls. Journal of Abnormal Child Psychology, 35, 969-981.

McCandless, S., \& O’Laughlin, L. (2007). The clinical utility of the behavior rating inventory of executive functioning (BRIEF) in the diagnosis of ADHD. Journal of Attention Disorders, 10, 381-389. 
Nigg, J. T. (2006). What causes ADHD? Understanding what goes wrong and why. New York: Guilford Press.

Ollendick, T. H., Jarrett, M. A., Wolff, J. C., \& Scarpa, A. (2009). Reactive and proactive aggression: Cross-informant agreement and the clinical utility of different informants. Journal of Psychopathology and Behavioral Assessment, 31, 51-59.

Parrish, J., Geary, E., Jones, J., Seth, R., Hermann, B., \& Seidenberg, M. (2007). Executive functioning in childhood epilepsy: Parent-report and cognitive assessment. Developmental Medicine \& Child Neurology, 49, 412-416.

Polman, H., de Castro, B. O., Koops, W., van Boxtel, H. W., \& Merk, W. W. (2007). A metaanalysis of the distinction between reactive and proactive aggression in children and adolescents. Journal of Abnormal Child Psychology, 35, 522-535.

Poulin, F., \& Boivin, M. (2000). Reactive and proactive aggression: Evidence of a two-factor model. Psychological Assessment, 12, 115-122.

Price, J. M., \& Dodge, K. A. (1989). Reactive and proactive aggression in childhood: Relations to peer status and social context dimensions. Journal of Abnormal Child Psychology, 17, 455-471.

Prifitera, A., Saklofske, D. H., \& Weiss, G. (Eds.) (2005). WISC-IV: Clinical use and interpretation. New York: Elsevier Science.

Prinstein, M. J., \& Cillessen, A. H. N. (2003). Forms and functions of adolescent peer aggression associated with high levels of peer status. Merrill-Palmer Quarterly, 49, 310-342.

Raine, A., Dodge, K., Loeber, R., Gatzke-Kopp, L., Lynam, D., Reynolds,...Liu, J. (2006). The reactive-proactive aggression questionnaire: Differential correlates of reactive and proactive aggression in adolescent boys. Aggressive Behavior, 32, 159-171. 
Rathert, J., Fite, P. J., Gaertner, A. E., \& Vitulano, M. (2011). Associations between effortful control, psychological control and proactive and reactive aggression. Child Psychiatry and Human Development, 42, 5, 609-21.

Richards, J. M., \& Gross, J. J. (2000). Emotion regulation and memory: The cognitive costs of keeping one's cool. Journal of Personality and Social Psychology, 79, 410-424.

Rothbart, M. K., \& Bates, J. E. (2006). Temperament. In N. Eisenberg, W. Damon \& R. M. Lerner (Eds.), Handbook of child psychology: Vol. 3. Social, emotional, and personality development (6th ed., pp. 99-166). Hoboken, NJ: Wiley.

Séguin, J. R., \& Zelazo, P. D. (2005). Executive function in early physical aggression. In J. Archer, R. E. Tremblay, W. W. Hartup, \& W. Willard (Eds.), Developmental origins of aggression (pp. 307-329). New York: Guilford.

Schoemaker, K., Bunte, T., Wiebe, S. A., Espy, K. A., Deković, M. and Matthys, W. (2012), Executive function deficits in preschool children with ADHD and DBD. Journal of Child Psychology and Psychiatry, 53, 111-119.

Stuss, D. T., \& Benson, D. F. (1987). The frontal lobes and control of cognition and memory. In E. Perecman (Ed.), The frontal lobes revisited (pp. 141-158). New York, NY: The IRBN Press.

Toplack, M. E., Bucciarelli, S. M., Jain, U., \& Tannock, R. (2009). Executive functions: Performance-based measures and the behavior rating inventory of executive function (BRIEF) in adolescents with attention deficit/hyperactivity disorder (ADHD). Child Neuropsychology, 15, 53-72. 
Vohs, Kathleen D. and Roy F. Baumeister (2004), “Understanding Self-Regulation: An Introduction," in Handbook of Self-Regulation: Research, Theory and Applications, ed. Roy F. Baumeister and Kathleen D. Vohs, New York: Guilford, 3-10.

Vitaro, F., Brendgen, M., \& Tremblay, R. E. (2002). Reactively and proactively aggressive children: Antecedent and subsequent characteristics. Journal of Child Psychology and Psychiatry, 43, 495-506.

Wechsler, D. (1991). Manual for the Wechsler intelligence scale for children (3rd ed.). San Antonio, TX: The Psychological Corporation.

Wechsler, D. (2003). Manual for the Wechsler intelligence scale for children (4th ed.). San Antonio, TX: The Psychological Corporation.

Welsh, M. C., \& Pennington, B. F. (1988). Assessing frontal lobe functioning in children: Views from developmental psychology. Developmental Neuropsychology, 4, 199-230.

Winstok, Z. (2009). From self-control capabilities and the need to control others to proactive and reactive aggression among adolescents. Journal of Adolescence, 32, 455-466.

Zhou, Q., Chen, S. H., \& Main, A. (2011). Commonalities and differences in the research on children's effortful control and executive function: A call for an integrated model of selfregulation. Child Development Perspectives, 6, 2, 112-121.

Zingerevich, C., \& LaVesser, P. D. (2009). The contribution of executive functions to participation in school activities of children with high functioning autism spectrum disorder. Research in Autism Spectrum Disorders, 3, 429-437. 
Table 1.

Sample Characteristics

\begin{tabular}{lcc}
\hline Gender & $\mathbf{n}$ & $\%$ \\
\hline Boy & 54 & 63.5 \\
\hline Girl & 31 & 36.5 \\
\hline Diagnoses & $\begin{array}{c}\text { Primary } \\
\text { diagnosis (n) }\end{array}$ & $\begin{array}{c}\text { Secondary } \\
\text { diagnosis }(\mathbf{n})^{\mathrm{b}}\end{array}$ \\
\hline ADHD & 33 & 19 \\
\hline Anxiety Disorders & 19 & 27 \\
\hline Mood Disorders & 6 & 6 \\
\hline $\begin{array}{l}\text { Oppositional Defiant Disorder } \\
\text { or Conduct Disorder }\end{array}$ & 6 & 11 \\
\hline $\begin{array}{l}\text { Learning Disability (Reading, } \\
\text { Writing, Math, or NOS) }\end{array}$ & 6 & 11 \\
\hline \begin{tabular}{l} 
Other \\
\hline
\end{tabular} & 13 & 19 \\
\hline
\end{tabular}

Note. Two of the 85 children did not receive a primary diagnosis even though they were referred for clinical evaluation. 67 of the 85 children (78.8\%) were comorbid with at least one secondary diagnosis. However, the numbers of secondary diagnoses do not add up to 67 because some children had more than one comorbid disorder. 
Table 2.

Zero-order Correlations among Study Variables

\begin{tabular}{|c|c|c|c|c|c|c|c|c|c|c|c|c|}
\hline & Mean & SD & 1 & 2 & 3 & 4 & 5 & 6 & 7 & 8 & 9 & 10 \\
\hline 1. Reactive Aggression & 8.30 & 3.31 & - & & & & & & & & & \\
\hline 2. Proactive Aggression & 4.51 & 2.38 & $.65^{* *}$ & - & & & & & & & & \\
\hline 3. Internalizing & 63.62 & 10.39 & $.21 *$ & .06 & - & & & & & & & \\
\hline 4. Externalizing & 61.09 & 14.51 & $.35^{* *}$ & $.27 * *$ & $.45^{* *}$ & - & & & & & & \\
\hline 5. Behavioral Regulation & 64.67 & 14.51 & $.48 * *$ & -.01 & $.53 * *$ & $.71 * *$ & - & & & & & \\
\hline 6. Metacognition & 68.74 & 9.76 & $.24 *$ & .00 & $.33^{* *}$ & $.28^{* *}$ & $.51 * *$ & - & & & & \\
\hline 7. Age & 10 & 2.82 & .10 & -.06 & $.25 *$ & -.02 & $.22 *$ & $.23^{*}$ & - & & & \\
\hline 8. Gender & 1.36 & .48 & $-.18^{*}$ & $.22 *$ & -.06 & -.04 & .06 & .12 & -.03 & - & & \\
\hline 9. IQ & 94.20 & 14.91 & .11 & -.12 & $-.21 *$ & -.08 & -.15 & -.05 & -.11 & -.12 & - & \\
\hline 10. ADHD & .64 & .48 & -.06 & .07 & -.09 & .05 & .03 & .10 & $-.38 * *$ & -.14 & .00 & - \\
\hline 11. Medication & .25 & .43 & -.03 & -.06 & -.06 & -.10 & -.10 & .05 & .02 & .13 & .09 & -.13 \\
\hline
\end{tabular}

Note. Means, SDs, and intercorrelations are presented for reactive and proactive aggression raw scores. Correlations with all other variables are presented for standardized residual aggression scores. For the CBCL and BRIEF, means, SDs, and correlations are presented for $T$ scores. Gender was coded male $=1$. IQ scores were missing for three children in the sample. ADHD was dichotomized; $1=$ any ADHD diagnosis present. Medication was coded $1=$ taking any psychotropic medication.* $\mathrm{p}<.05$ (1-tailed), $* * \mathrm{p}<.01$ (1-tailed). 
Table 3.

Explanation of the Effect of Reactive Aggression on Internalizing and Externalizing Behavior Problems by Behavioral Regulation and Metacognition Skill Difficulties

\begin{tabular}{|c|c|c|c|c|c|c|}
\hline Analysis & Dependent Variable & Predictors & $\mathrm{B}$ & SE B & $\beta$ & Total $\mathrm{R}^{2}$ \\
\hline \multirow[t]{2}{*}{1.} & CBCL Internalizing & Behavioral Regulation & .40 & .08 & $.56^{* * *}$ & \\
\hline & & Reactive Aggression & -.60 & 1.11 & -.06 & $.29 * * *$ \\
\hline \multirow[t]{2}{*}{2.} & CBCL Internalizing & Metacognition & .31 & .11 & $.29 * *$ & \\
\hline & & Reactive Aggression & 1.49 & 1.11 & .14 & $.13 * *$ \\
\hline \multirow[t]{2}{*}{3.} & CBCL Externalizing & Behavioral Regulation & .56 & .07 & $.71 * * *$ & \\
\hline & & Reactive Aggression & .09 & 1.00 & .01 & $.50 * * *$ \\
\hline \multirow[t]{2}{*}{4.} & CBCL Externalizing & Metacognition & .24 & .12 & $.21 *$ & \\
\hline & & Reactive Aggression & 3.35 & 1.18 & $.30 * *$ & $.16^{* *}$ \\
\hline
\end{tabular}

Note: Regressions were conducted using standardized residual scores for reactive and proactive aggression and using $T$ scores for CBCL and BRIEF scales. ${ }^{*} p<.05 ; * * p<.01 ; * * * p<.001$ (2-tailed) 